r ScIDioc

\section{Cytotoxicity of Different Degrees of De-Acetylated Chitosan on 3T3- and Two Human Tooth Fibroblast Cell-Lines}

Research Article

SR Grobler ${ }^{1 *}$, A Olivier ${ }^{1}$, HW Kruijsse ${ }^{1}$, VT Perchyonok ${ }^{2}$

${ }^{1}$ Oral and Dental Research Institute, Faculty of Dentistry, University of the Western Cape, Private Bag X1, Tygerberg 7505, Cape Town, South Africa.

${ }^{2}$ VTPCHEM PTY LTD, Glenhuntly, 3163, Melbourne, Australia.

\section{Abstract}

Nowadays chitosan becomes more and more important as a drug carrier. In this study the influence of different degrees of de-acetylation of chitosan on the cytotoxicity were investigated.

Materials and Methods: Chitosan (87\%, 70\% and 40\% de-acetylated) was analysed for their cytotoxic effect on mouse Balb/c 3T3 fibroblast cells as well as two different human tooth pulp fibroblast cell-lines. The cell survival rate was determined over a 24 hour period according to the standard MTT assay.

Results: The Univariate ANOVA test showed significant differences in the cell survival rates $(\mathrm{p}<0.01)$ amongst $87 \%$ and $70 \%$ and $40 \%$ de-acetylated chitosan products for the $3 \mathrm{~T} 3$ as well as the two pulp fibroblast cell-lines. Significant differences were also found between both tooth cell-lines and the 3T3 cell-line at all 3 different deacetylated chitosan levels. The 3T3 cell line was mostly affected at 40\% de-acetylation. The difference between both human cell-lines was not significant.

Conclusion: The lower the degree of chitosan de-acetylation the less the cell survival rate while an $87 \%$ deacetylation degree improved the cell survival rate. Different cell lines react differently towards different degrees of de-acetylation. The relative survival rates of different cell lines changed at different degrees of de-acetylation.

Keywords: Chitosan; Degrees De-Acetylated; Cytotoxicity; 3T3; Tooth Fibroblasts.

\section{Introduction}

Due to the increasing applications of nanoparticles in many fields' becomes more and more under investigation. Especially, a growing concern is the possible adverse effects of exposure to nanoparticles. Therefore, cytotoxicity studies became more and more important. Of the most important factors to consider during such cytotoxicity studies are the cell type used, and in the case of chitosan, the degree of de-acetylation (DDA). Preferably the cell type under investigation should be the chitosan target cell.

Chitosan [1] is produced commercially by de-acetylation of chitin and is a natural cationic polysaccharide composed of randomly distributed $\beta$-1, 4-linked D-glucosamine and $\mathrm{N}$-acetyl $\alpha$-glucosamine.

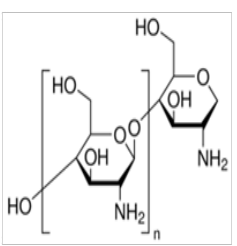

This cationic nature is something special as most polysaccharides are neutral or negatively charged in an acidic environment [2]. The cationic nature allows it to form electrostatic complexes or multilayer structures with other negatively charged molecules. Chitosan is non-toxic, biocompatible, bio-degradable and has mucous-adhesive properties and as a result became widely used in the pharmaceutical field as a carrier system for drugs, hormones, proteins, enzymes and genes [3-6]. Chitosan can be successfully used as a drug carrier because it will solubilize and degrade in an acidic environment with the resultant release of the drug [7]. However

\footnotetext{
*Corresponding Author:

SR Grobler,

Oral and Dental Research Institute, Faculty of Dentistry, University of the Western Cape, Private Bag X1, Tygerberg 7505, Cape Town, South Africa.

E-mail: tamaraperchyonok@gmail.com.
}

Received: September 21, 2016

Accepted: October 13, 2016

Published: October 17, 2016

Citation: SR Grobler, A Olivier, HW Kruijsse, VT Perchyonok (2016) Cytotoxicity of Different Degrees of De-Acetylated Chitosan on 3T3-and Two Human Tooth Fibroblast Cell-Lines. Int J Dentistry Oral Sci. 3(10), 337-339. doi: http://dx.doi.org/10.19070/2377-8075-1600068

Copyright: SR Grobler ${ }^{\circ}$ 2016. This is an open-access article distributed under the terms of the Creative Commons Attribution License, which permits unrestricted use, dist ibution and reproduction in any medium, provided the original author and source are credited. 
the low solubility in alkaline and neutral medium has a negative influence on the use. Chitosan is hypoallergenic and has natural antibacterial properties, which further support its use in the army as field bandages [8]. Furthermore, antioxidant-chitosan hydrogels (that of resveratrol, propolis and $\beta$-carotene) were found to significantly improve the bond strength to dentine with or without phosphoric acid pre-treatment [9] as many other hydrogels do [10].

\section{Materials and Methods}

Chitosan (Aldrich, Australia) were used as received. The degree of de-acetylation of typical commercial chitosan used in this study was $87 \%$ and the molecular weight $2500 \mathrm{kDa}$. The isoelectric point was 4.0-5.0.

For the other de-acetylated products: Chitin was de-acetylated to $\sim 70 \%$ (mw $45 \mathrm{kDa}$ ) and $\sim 40 \%$ (mw $15 \mathrm{kDa}$ ) by the use of $45 \%$ sodium hydroxide solution in a 1:10 (W/V) ratio in a reaction vessel following Zhang's method [11] and the reaction was under nitrogen atmosphere [12]. A Balb/c 3T3 mouse fibroblast cell line (The National Repository for Biological Materials, Sandringam) was maintained and cultured under standard conditions [13]. The two human dental pulp fibroblast cultures were established as previously described [14-16]. Briefly freshly extracted impacted $3^{\text {rd }}$ molars were collected in Dubecco's Modified Eagels Medium, the middle third of the pulp cultured and the cells between the $3^{\text {rd }}$ and $5^{\text {th }}$ passage used.

The cytotoxicity study was done as previously reported [13-16]. Briefly, the cells (mouse 3T3 Balb/c fibroblast, human tooth fibroblast 1 or human tooth fibroblast 2) were first grown to near confluency, diluted to a final cell suspension containing approximately $3 \times 10^{5}$ cells $/ \mathrm{ml}$ and plated out in sets of 96 well plates. Chitosan $87 \%$ de-acetylated, $70 \%$ de-acetylated or $40 \%$ de-acetylated were then added to the growth medium at a concentration of $1 \mathrm{mg} / \mathrm{ml}$. Two hundred $\mu \mathrm{l}$ of each group was added to 20 wells in the 96 well plates. Medium without any gels was used as controls. After 24 hours the well-known MT'T colorimetric assay was used to evaluate the cell survival rate. Absorbance was measured at wavelength $540 \mathrm{~nm}$ on a spectrophotometer to determine the number of viable cells. Three replicates were done in each group.

\section{Results}

The Figure shows the cell survival rates with 95\% confidence level error bars of the mouse Balb/c 3T3 fibroblast cell line, the human1 tooth pulp fibroblast cell-line and human2 tooth pulp fibroblast cell-line at 87\% de-acetylated chitosan, 70\% de-acetylated chitosan and $40 \%$ de-acetylated chitosan.

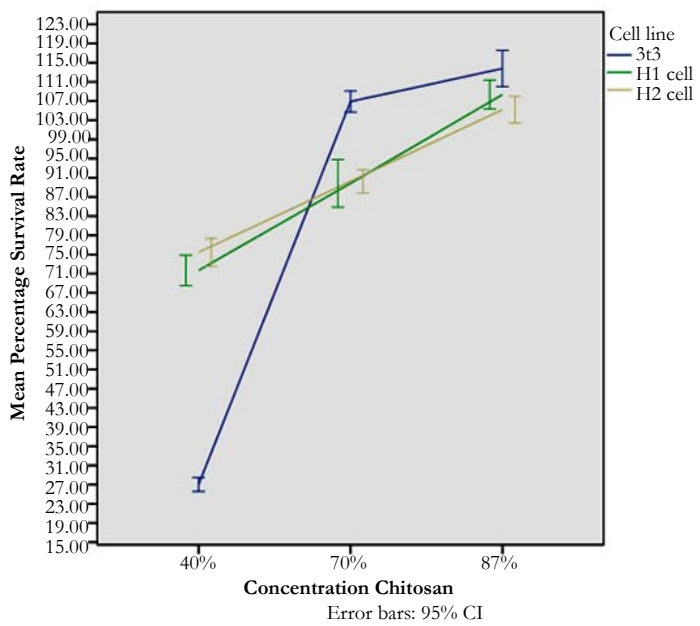

The results of a Univariate ANOVA showed significant main effects and an interaction effect suggesting an effect of increase in the concentration of chitosan.

Cell-line: $\mathrm{F}_{(2,438)}=23.71 ; \mathrm{p}<0.001$

Concentration: $\mathrm{F}_{(2,4378)}=1120.8 ; \mathrm{p}<0.001$

Cell-Line*Concentration: $\mathrm{F}_{(4,438)}=233.1 ; \mathrm{p}<0.001$

Significant differences were found between the two human celllines and the 3T3 cell-line at all 3 different de-acetylated chitosan levels. The difference between both human cell-lines is not significantat all 3 different de-acetylated chitosan levels (see Table below).

\section{Discussion}

We determined the survival rates at a growth medium concentration of $1 \mathrm{mg} / \mathrm{ml}$ which is reported to be in line with other research and which may be considered as on the upper recommended level [16] of concentration. The three cell lines tested consisted of a standard cell line bought from the National Repository for Biological Materials and two self-established human tooth pulp fibroblast cell lines (H1 cell line and $\mathrm{H} 2$ cell line) from two different people. To our knowledge until now different degrees of de-acetylation towards the mentioned cell lines were not reported.

\begin{tabular}{|c|c|c|c|c|c|}
\hline \multirow{2}{*}{ Cell-line } & $\begin{array}{c}\text { De-acetylation } \\
\text { concentration }\end{array}$ & \multirow{2}{*}{ Mean } & \multirow{2}{*}{ Std. Error } & \multicolumn{2}{|c|}{ 95\% Confidence Interval } \\
\cline { 5 - 6 } & & & Lower Bound & Upper Bound \\
\hline \multirow{3}{*}{3 t3 } & $40 \%$ & 27.028 & 1.406 & 24.264 & 29.791 \\
\cline { 2 - 6 } & $70 \%$ & 106.894 & 1.179 & 104.577 & 109.212 \\
\cline { 2 - 6 } & $87 \%$ & 115.399 & 1.456 & 112.538 & 118.26 \\
\hline \multirow{3}{*}{ H1cell } & $40 \%$ & 72.370 & 1.422 & 69.574 & 75.165 \\
\cline { 2 - 6 } & $70 \%$ & 89.883 & 1.473 & 86.987 & 92.779 \\
\cline { 2 - 6 } & $87 \%$ & 107.714 & 1.198 & 105.360 & 110.069 \\
\hline \multirow{3}{*}{ H2cell } & $40 \%$ & 74.807 & 1.208 & 72.433 & 77.181 \\
\cline { 2 - 6 } & $70 \%$ & 90.260 & 1.362 & 87.584 & 92.936 \\
\cline { 2 - 6 } & $87 \%$ & 103.127 & 1.492 & 100.196 & 106.059 \\
\hline
\end{tabular}


Different degrees of de-acetylation (DDA) of chitosan is normally obtained by the treatment of chitin with alkali and a higher DDA is obtained by increasing the time and temperature, while the molecular weight ( $\mathrm{mw}$ ) of chitosan is dependent on the initial source of material which could be crap, fungi, shrimp etc. This mw normally decreases in the process to obtain a higher DDA [12]. In this study an $87 \%$ product with a mw of $2500 \mathrm{kDa}$ was used as received, while the $70 \%$ (mw $145 \mathrm{kDA}$ ] and $40 \%$ (mw $15 \mathrm{kDA}$ ) were prepared. We did not investigate the effect of the molecular weight of the different chitosan's on the cytotoxicity.

It was reported that the degree of de-acetylation (DDA) and the molecular weight are important parameters which determines many physiochemical and biological properties of chitosans [12]. Nunthanid [17] reported that chitosans with high mw have higher moisture adsorption and tensile strength than those with the same DDA but lower mw. Hidaka [18] reported that a 94\% DDA chitosan membranes gave minimal film degradation, mild inflammatory reaction and minimal osteogenesis while between 65 to $80 \%$ gave the opposite response.This effect is more or less in line to our survival rate results for all three different cell lines (Figure) that the higher the degree of de-acetylation the more the survival rate and that $87 \%$ de-acetylation actually improved the cell survival rate to above $100 \%$.

However, Hamilton [19] reported no relationship between the DDA of chitosan, mw or growth of cells. While a similar report by the growth of keratinocytes was noted [20]. From the above it is concluded that there is controversial statements as far as the effect of molecular weights, in general, are concerned. In our study, the mw of the three chitosan products differed from $2500 \mathrm{kDa}$ through $145 \mathrm{kDa}$ to $15 \mathrm{kDa}$ but this effect was not investigated.

In this study (Figure) we found that a $40 \%$ de-acetylation chitosan affects the 3T3 cell line significantly more (only about 30\% cell survival was found) than both the two pulp cell lines. However, the other way round was found both at $70 \%$ and $87 \%$ de-acetylation where the pulp cell lines were significantly more affected (Figure). This showed that the relative survival rates of different cell linescan also change at different degrees of de-acetylation. The above finding is in line where it was reported that different cell lines have different levels of cytotoxicity towards a dentine bonding agent $[14,15]$. In one study where 3 different human pulp fibroblast cell lines were studied it was found that one of these pulp cell lines were less cytotoxic than the 3T3 cell line but the other 2 were more sensitive.

\section{Conclusion}

The lower the degree of chitosan de-acetylation the less the cell survival rate while an $87 \%$ de-acetylation degree improved the cell survival rate. Different cell lines react differently towards different degrees of de-acetylation. The relative survival rates of different cell lines changed at different degrees of de-acetylation.

\section{References}

[1]. Shenderova OA, Hens SAC (2010) Detonation nanodiamondparticles processing, modification and bioapplications. In: Nanodiamonds. Springer Us. 79-116.

[2]. Cheung RCF, Ng TB, Wong JH, Yee Chan WY (2015) Chitosan: An Update on Potential Biomedical and Pharmaceutical Applications. Mar Drugs. 13(8): 5156-5186.

[3]. Ahn MR, Kunimasa K, Ohta T, Kumazawa S, Kamihira M, et al., (2007) Suppression of tumor-induced angiogenesis by Brazilian propolis: Major component artepillin $\mathrm{C}$ inhibits in vitro tube formation and endothelial cell proliferation. Cancer Lett. 252 (2): 235-243.

[4]. Amaral, RC, Gomes RC, Rocha Dos Santos WM, Abreu SLR, et al., (2006) Periodontitis treatment with Brasilian green propolis gel. Pharmacologyonline. 3: 336-341.

[5]. Bankova V, Christov R, Kujumgiev A, Marcucci MC, Popov S (1995) Chemical composition and antibacterial activity of Brazilian propolis. Z Naturforsch C. 50 (3/4): 167-172.

[6]. Bankova VS, Christov R, Popov S, Marcucci MC,Tsvetkova I, et al., (1999) Antibacterial activity of essential oils from Brazilian propolis. Fitoterapia 70 (2): 190-193.

[7]. Bankova V, Popova M, Trusheva B (2007) Plant origin of propolis: Latest developments and importance for research and medicinal use. Apicultura - De la stiinta la agribusiness si apiterapie, Editura Academic Press. 40-46.

[8]. Aoi W, Hosogi S, Niisato N, Yokoyama N, Hayata H et al., (2013) Improvement of insulin resistance, blood pressure and interstitial $\mathrm{pH}$ in early developmental stage of insulin resistance in OLETF rats by intake of propolis extracts. Biochem Biophys Res Commun. 432(4): 650-653.

[9]. Perchyonok VT, Reher V, Zhang S, Basson NJ, Grobler SR (2015) Bioinspired-Interpenetrating Network (IPNs) Hydrogel (BIOF-INPs) and TMD in Vitro: Bioadhesion, Drug Release and Build in Free Radical Detection and Defense. OJST. 5(3): 53-61.

[10]. Perchyonok VT, Reher V, Zhang S, Basson NJ, Grobler SR (2015) BioactiveFunctionalized Interpenetrating Network Hydrogel (BIOF-IPN): A Novel Biomaterial Transforming the Mechanism of Bio-Repair, Bio-Adhesion and Therapeutic Capability - An In Vitro Study. J Interdiscipl Med Dent Sci. 3: $1-5$.

[11]. Zhang ZT, Chen DH, Chen L (2002) Preparation of two different serials of chitosan. J Dong Hua Univ. 19(3): 36-39.

[12]. Yuan Y, Chesnutt BM, Haggard WO, Bumgardner JD (2011) Deacetylation of chitosan: Material characterization and in vitro evaluation via albumin adsorption and pre-osteoblastic cell cultures. Materials. 4(8): 1399-1416.

[13]. Tamara VT, Grobler S, Zhang S, Olivier A, Oberholzer T (2013) Insights into chitosan hydrogels on dentine bond strength and cytotoxicity. OJST. 3: $75-82$.

[14]. Grobler SR, Olivier A, Moodley D, Kotze TvW (2004) Cytotoxicity of two concentrations of a dentine bonding agent on mouse 3T3 and human fibroblast cell lines. SADJ. 59(9): 368-372.

[15]. Moodley D, Grobler SR, Olivier A (2005) Cytotoxicity of a dentine bonding agent on four different cell lines. SADJ. 60(6): 234-236.

[16]. Grobler SR, Olivier A, Perchyonok TV, Moodley D, Osman Y (2014) Cytotoxic effect of chitosan- $\mathrm{H}$, resveratrol, b-carotene and propolis and their chitosan hydrogels on Balb/c mouse 3T3 fibroblast cells. Inter J Dent Oral Science.1(2): 10-14.

[17]. Zhang H, Neau SH (2001) In vitro degradation of chitosan by a commercial enzyme preparation: Effect of molecular weight and degree of deacetylation. Biomaterials. 22(12): 1653-1658.

[18]. Hidaka Y, Ito M, Mori K, Yagasaki H, KafrawyAH (1999) Histpathologi$\mathrm{cal}$ and immunohistochemical studies of membranes of deacetylated chitin derivatives implanted over rat calvaria. J Biomed Mater Res. 46(3): 418-423.

[19]. Hamilton V, Yuan Y, Rigney DA, Chesnutt, BM, Puckett AD, et al., (2007) Bone cell attachment and growth on well-characterized chitosan films. Polym Int. 56(5): 641-647.

[20]. Chatelet C, Damour O, Domard A (2001) Influence of the degree of acetylation on some biological properties of chitosan films. Biomaterials. 22: 261-268. 